\title{
Thermal Stability Improvement and Structural Change of Oil Gels Formed by Styrene-Butadiene-Styrene Triblock Copolymer Induced by Adding Poly(phenylene ether)
}

\author{
Kouichi Kato $^{1 *}$, Yuki Tsukamoto ${ }^{2}$, Eri Hirai², Yasuhiro Matsuda ${ }^{2,3}$, Shigeru Tasaka ${ }^{2,3}$ \\ ${ }^{1}$ Department of Opto-Electronics and Nanostructure Science, Shizuoka University, Hamamatsu, Japan \\ ${ }^{2}$ Department of Materials Science and Chemical Engineering, Shizuoka University, Hamamatsu, Japan \\ ${ }^{3}$ Department of Applied Chemistry and Biochemical Engineering, Shizuoka University, Hamamatsu, Japan \\ Email: ${ }^{*}$ k kato@shizureki.co.jp
}

Received 25 August 2014; revised 19 September 2014; accepted 12 October 2014

Copyright (C) 2014 by authors and Scientific Research Publishing Inc.

This work is licensed under the Creative Commons Attribution International License (CC BY).

http://creativecommons.org/licenses/by/4.0/

(c) (i) Open Access

\section{Abstract}

The thermal stability of oil gels formed by styrene-butadiene-styrene triblock copolymer (SBS) was improved by adding a small amount of poly(phenylene ether) (PPE), which has a higher glass transition temperature (Tg). In naphthenic oil which is a good solvent for the butadiene blocks, but a non-solvent for the styrene blocks and PPE, PPE was selectively included into styrene blocks in SBS, and induced the increase of the Tg of these blocks. The melting temperature determined by viscoelastic measurements and softening temperature of the gels were elevated by adding PPE, while no significant change was detected by adding polystyrene. The gel became opaque by adding PPE, and partially separated phases were observed by field emission scanning electron microscopy (FE-SEM). The dependence of the viscoelastic behavior on the PPE concentration can be explained by the structural change observed by FE-SEM.

\section{Keywords}

Styrene-Butadiene-Styrene Triblock Copolymer, Poly(phenylene ether) (PPE), Oil Gel, Naphthenic Oil

\footnotetext{
${ }^{*}$ Corresponding author.
}

How to cite this paper: Kato, K., Tsukamoto, Y., Hirai, E., Matsuda, Y. and Tasaka, S. (2014) Thermal Stability Improvement and Structural Change of Oil Gels Formed by Styrene-Butadiene-Styrene Triblock Copolymer Induced by Adding Poly(phenylene ether). Open Journal of Organic Polymer Materials, 4, 65-73. http://dx.doi.org/10.4236/ojopm.2014.44009 


\section{Introduction}

ABA triblock copolymers with two polystyrene end blocks connected by an elastic midblock are rubbery elastomers with thermo plasticity and excellent workability. Oil gels can be formed by dissolving these triblock copolymers in selective solvents for the midblock, and many investigations have been performed to investigate the morphology [1]-[7], and thermal and viscoelastic properties [2]-[6] [8] of ABA triblock copolymer oil gels. By the structure formed by aggregating styrene blocks and bridging chains of the mid-blocks in selective solvents for the mid-blocks [1]-[4], these triblock copolymers also form micelles in such solvents [9] [10].

Styrene-butadiene-styrene triblock copolymer (SBS) is a typical ABA triblock copolymer excelling in compatibility with oil solvents and forming oil gels [11] [12]. SBS is an excellent soft material in flexibility, however it is thermally instable due to its low fluid temperature below the glass transition temperature ( $\mathrm{Tg}$ ) of the styrene blocks [6] [8] [11]. Although SBS is widely used as an adhesive material, its thermal instability limits its application at a high temperature.

One of the major applications of SBS is an additive of asphalt to improve its thermal and mechanical strength. The use of SBS-modified asphalt has gained importance in road or roof construction [13]. In asphalt modified with SBS, the styrene and butadiene blocks in SBS are preferentially soluble in asphaltene and maltene, respectively, which are two major compositions of asphalt [14]. The softening temperature of asphalt is increased by modifying with SBS because of the elevated Tg of the styrene blocks by selective compatibility with asphaltene. Because asphalt is used at various temperatures including temperatures as high as $100^{\circ} \mathrm{C}$, the thermal stability of asphalt modified with SBS is expected to be improved by increasing Tg of the styrene blocks in added SBS.

One of the promising methods to improve the thermal stability of SBS is to increase the Tg of the styrene blocks by adding polymers with higher Tg. Because these polymers with high Tg need to be included selectively in the styrene blocks, these polymers need to have high affinity to the styrene blocks and low affinity to the butadiene blocks. Poly(phenylene ether) (PPE) is a heat resisting resin that can be soluble in only PS and PS blocks in SBS like asphaltene [15]-[19], and the blend of PS and PPE is widely used as a typical polymer blend [20][22]. Blending with PPE is an efficient approach to improve the thermal properties of PS or ABA triblock copolymers having PS end blocks [16] [20] [21] [23] [24].

Adding PPE can improve the thermal stability of SBS oil gels. But in order to make PPE included in the styrene blocks in SBS gels, not only the affinities among PPE, the styrene and butadiene blocks, but also the affinities among the polymers and the solvent should be considered. This complexness has prevented to understand SBS oil gels modified with PPE.

In this paper, SBS oil gels modified with PPE were prepared by using naphthenic oil which is a good solvent for the butadiene blocks, but a non-solvent for the styrene blocks and PPE. The rheological behaviors and thermal stabilities of the SBS gels were investigated, and the structures of the gels were discussed based on the results obtained by field emission scanning electron microscopy (FE-SEM) with the aid of the structures of SBS reported in the previous studies.

\section{Experimental}

\subsection{Materials}

The SBS sample used in this study was Kraton D 1101J with styrene content of $31 \mathrm{wt} \%$ (Kraton Polymer Japan). The PPE sample was obtained from Sigma Aldrich (catalog No. 181781-5G). Polystyrene (PS) was used to compare the influence of PPE and that of PS on the properties of SBS gels. YS Resin SX100 of Yasuhara Chemical was used for this purpose. The source of naphthenic oil was DIANA FRESIA NS90 produced by Idemitsu Kosan. The solubility parameters of PS, polybutadiene, and naphthenic oil were 17.5 - 18.5 [25], 17.1 [25], and 16.7 [26], $\mathrm{MPa}^{1 / 2}$, respectively. PPE was insoluble in naphthenic oil at the temperatures that we investigated $\left(<210^{\circ} \mathrm{C}\right)$.

\subsection{Sample Preparation}

Mixtures of SBS, PPE, and naphthenic oil were prepared by blending at $190^{\circ} \mathrm{C}$ for $20 \mathrm{~min}$ and cooling at ambient temperature. In this study, samples which did not flow 24 hours after inversing sample bottles at room temperature were defined as gels. 


\subsection{Measurements}

The softening temperature was measured at a heating rate of $5^{\circ} \mathrm{C} / \mathrm{min}$ in glycerin by ring and ball method, according to JIS K2207. The viscoelastic behaviors of the gels were measured with a piezo driving dynamic viscoelastic measuring instrument (PZ-PHEO NDS-1000). The frequency was fixed to $2 \mathrm{~Hz}$. Circular sheet samples with thickness of $1 \mathrm{~mm}$ and diameter of $5 \mathrm{~mm}$ was heated at a rate of $5^{\circ} \mathrm{C} / \mathrm{min}$. Field emission scanning electron microscopy (FE-SEM) was carried out with a JSM7001F (JEOL). The solvent of the SBS gel was eluted by ultrasonic cleaning with isopropanol, and isopropanol was removed by vacuum drying. The surface of the sample was coated with gold by spattering for observation of the structure of the SBS xerogels. The weight ratio of SBS to naphthenic oil in all the samples for viscoelastic, softening temperature measurements, and FE-SEM was fixed to SBS:naphthenic oil $=1: 4$.

\section{Results and Discussion}

\subsection{Gelation Condition}

Figure 1 shows ternary phase diagrams of SBS, PPE, and naphthenic oil. While $20 \mathrm{wt} \%$ of SBS was necessary to form gels without PPE in naphthenic oil, the mixtures with only $15 \mathrm{wt} \%$ of SBS was gelated in naphthenic oil by adding $5 \mathrm{wt} \%$ of PPE. This behavior indicates that PPE promotes the gelation of SBS in naphthenic. Photographs of some typical gels are shown in Figure 2. The decrease of the transparency of the gels suggests the existence of partially immiscible phases of PPE and the styrene blocks.

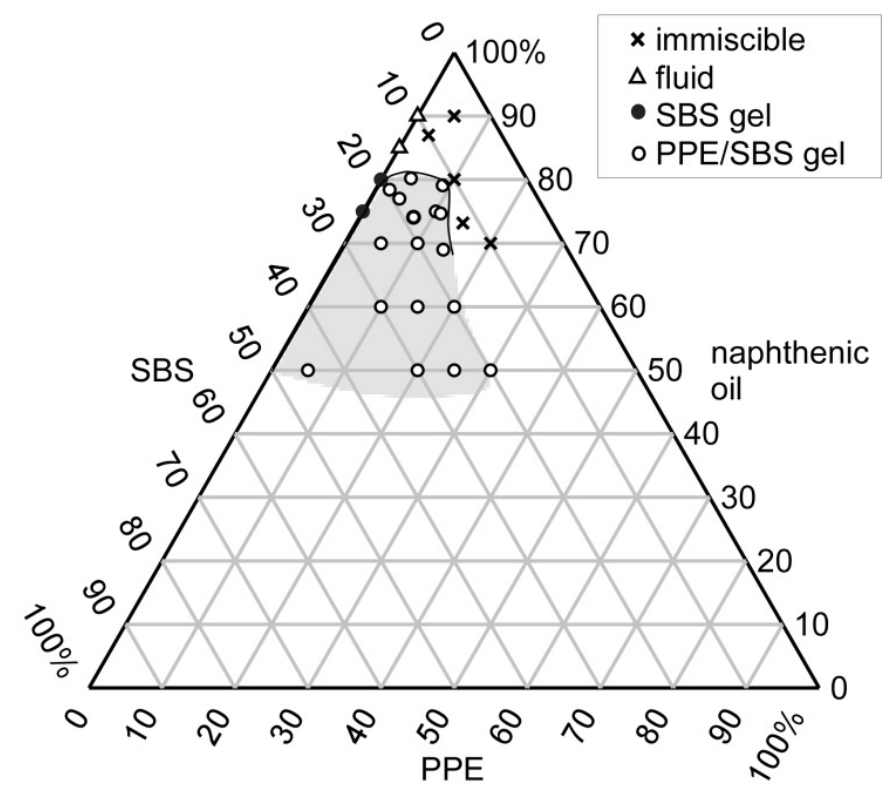

Figure 1. Ternary phase diagrams of the mixtures of SBS, PPE, and naphthenic oil.

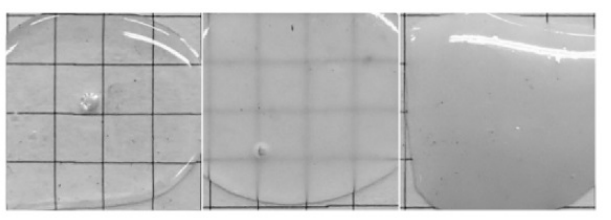

PPE

0

4.8

13.0

SBS

20.0

19.0

17.4

naphthenic oil

80.0

76.2

69.6

Figure 2. Photographs of typical SBS gels. 


\subsection{Dynamic Viscoelasticity and Thermal Stability of SBS Gels}

Figure 3 and Figure 4 summarize the viscoelastic behaviors of the SBS gels at $20^{\circ} \mathrm{C}$. The weight ratio of SBS to oils was fixed in Figure 4 (SBS:naphthenic oil = 1:4). The storage modulus E' of the SBS gel without PPE increased drastically with an increase of SBS content around $20 \mathrm{wt} \%$ in naphthenic oil, which suggests a morphological change of SBS around this concentration. The E' of the SBS gels with PPE in naphthenic oil slightly decreased, then increased drastically with an increase of PPE content. The relation between the viscoelastic behaviors and morphological changes will be discussed later.

The thermal stability of the SBS gels with added PPE in naphthenic oil was investigated by softening temperature measurements shown in Figure 5. Whereas the softening temperatures of the SBS gels with added PS were essentially same as that of the SBS gel without added homopolymers, the softening temperatures of the SBS gels were increased by adding PPE. This result clearly shows that the thermal stability of SBS gel can be improved not by increasing the amount of aggregating styrene domains, but by elevating their Tg by adding PPE [16]-[18] [20] [21] [24].

Temperature dependence of the viscoelastic behavior of the SBS gels with PPE in naphthenic oil is summarized in Figure 6. Whereas the temperature dependence of E' of SBS gel with added PS was essentially identical
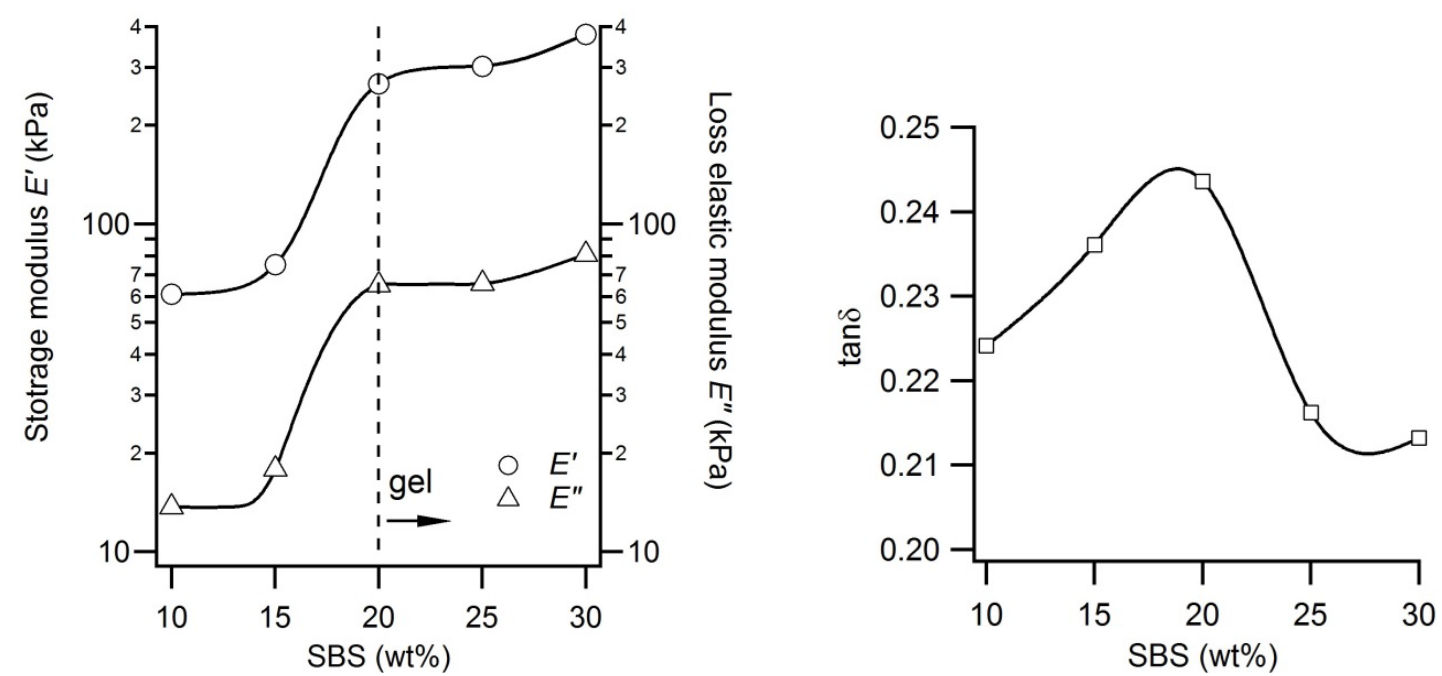

Figure 3. SBS concentration dependence of the viscoelastic behaviors of SBS/naphthenic oil gel.
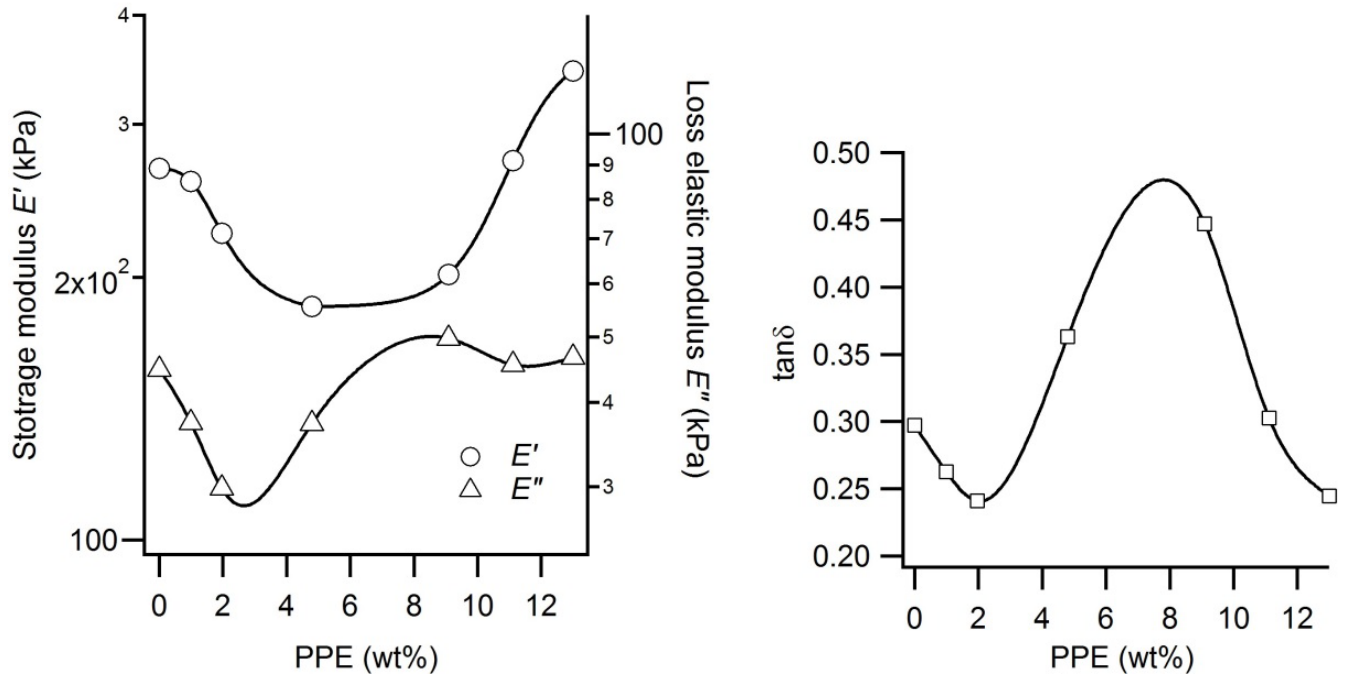

Figure 4. PPE concentration dependence of the viscoelastic behaviors of PPE/SBS/naphthenic oil gel. 


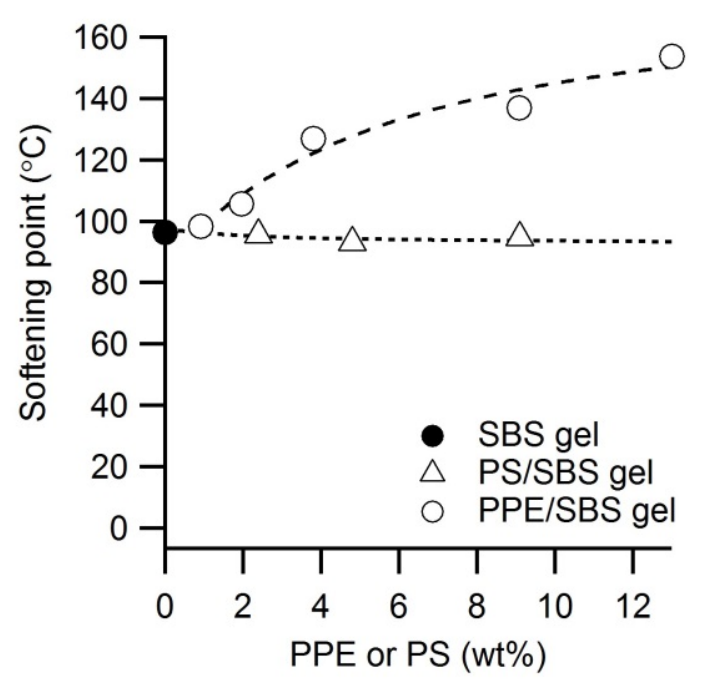

Figure 5. Softening temperatures of the SBS gels with PPE or PS in naphthenic oil.
O SBS(20wt\%) gel
$\diamond \mathrm{PS}(13.0 \mathrm{wt} \%) / \mathrm{SBS} \mathrm{Gel}$
$\triangle \mathrm{PPE}(3.8 \mathrm{wt} \%) / \mathrm{SBS}$ Gel
$\square \operatorname{PPE}(13.0 \mathrm{wt} \%) / \mathrm{SBS}$ Gel

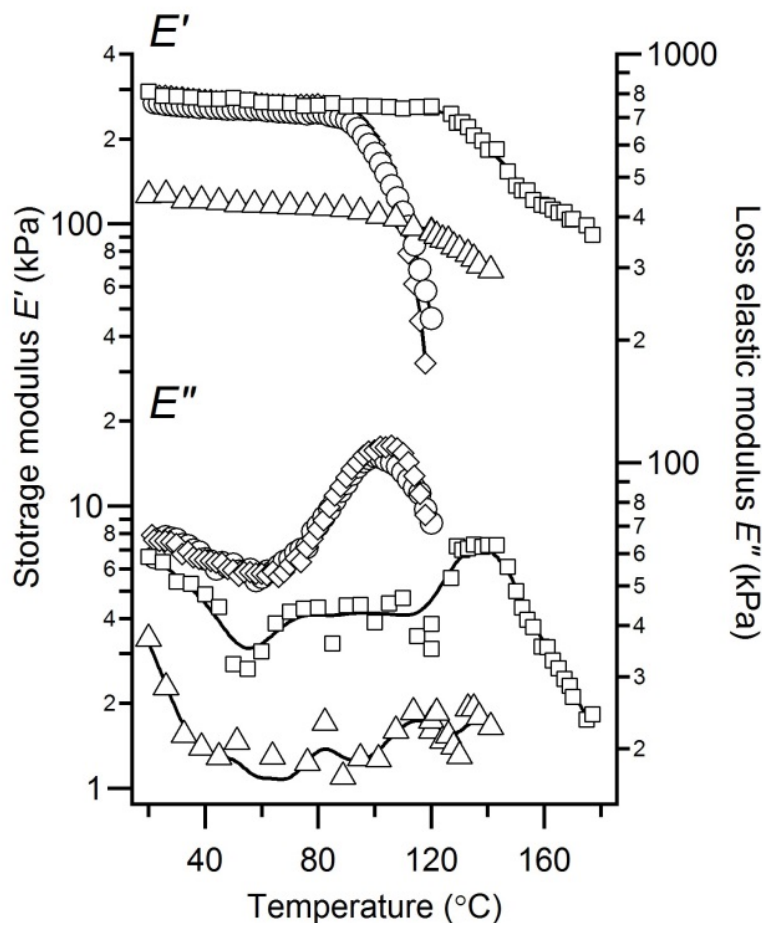

Figure 6. Temperature dependence of the viscoelastic behaviors of the SBS oil gels.

to that of SBS gel without added homopolymers, the temperature at which E' decreased drastically was elevated by the addition of PPE to the SBS gels in naphthenic oil. The decrease of E' in the SBS gels with added PPE was more gradual than that of the SBS gels without PPE, which will be discussed later. 


\subsection{The Structures of SBS Xerogel}

The structures of SBS xerogels were observed by FE-SEM as shown in Figure 7. The surface of the SBS xelogel without PPE was flat, and no other structure was observed. On the other hand, uniformly dispersed spherical clusters were observed in the micrographs of SBS xerogel with PPE, and the clusters become lager at higher concentration of PPE. The difference of the surface structures suggests that the spherical clusters are phases of PPE immiscible with styrene domains. Figure 8 shows micrographs of defects of the SBS xerogels with PPE. Styrene domains with PPE are stretched and ripped. The voids were observed in the cross section of SBS xerogel with lower weight ratio of PPE (SBS:PPE $=4: 1$ ), and the spherical clusters are included in the stretched part of styrene domains were observed in the micrographs of SBS xerogel with higher weight ratio of PPE (SBS:PPE $=4: 3$ ). Furthermore, the structure which is stretched long range with a width suggests the existence of a two dimensional continuous structure of styrene domains with PPE. Because the structure of styrene domains with PPE is changed depending on PPE concentration, the results of the observation by SEM may correlate with PPE concentration dependence of the E' changes as shown in Figure 4.

\subsection{The Structures of SBS Gels}

Based on the experimental results, the structures of SBS in the oil gels will be discussed in this section. It is widely accepted that SBS gels were formed by a network structure with aggregating styrene domains and crosslinking butadiene chains in selective solvents for the butadiene blocks [1]-[5]. Because the aggregating styrene domains prevent the flow of the butadiene chains [6] [8] [11] [24], affinity between the styrene domains and solvents dominates the strength of the aggregation and the gelation behavior of SBS. Because PPE can be blended in PS [17]-[19], PPE added to SBS gels is expected to be included in the styrene domains in SBS gels.

The minimum concentration of SBS for gelation was decreased by adding PPE in naphthenic oil, which indicates that PPE included in the styrene domains promoted the aggregation and gelation of SBS. The promotion of the gelation induced by PPE is reasonable because the solubility of the styrene blocks was decreased by the ad-

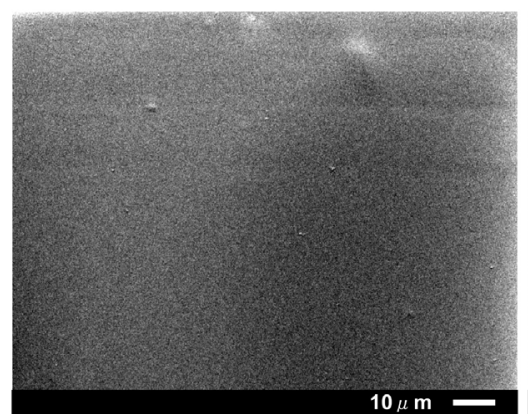

(a)

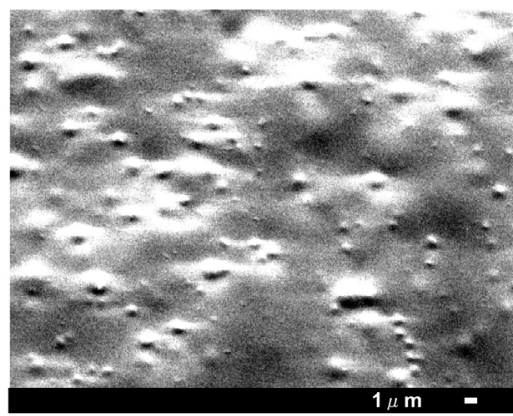

(b)

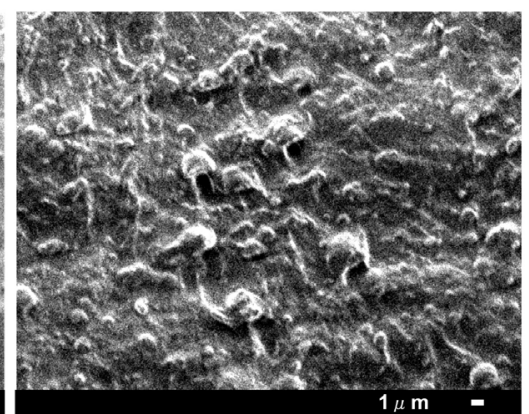

(c)

Figure 7. Field emission scanning electron micrographs of xerogels surface with weight ratio of (a) SBS:PPE = 4:0, (b) SBS:PPE $=4: 1$ and (c) SBS:PPE $=4: 3$.

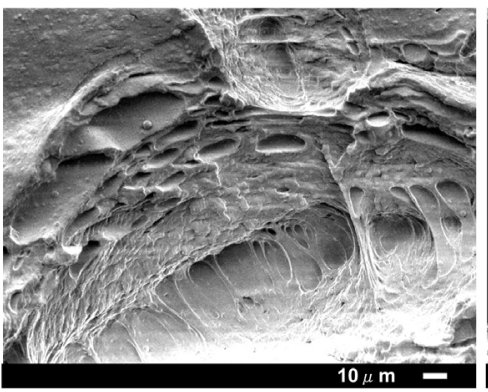

(a)

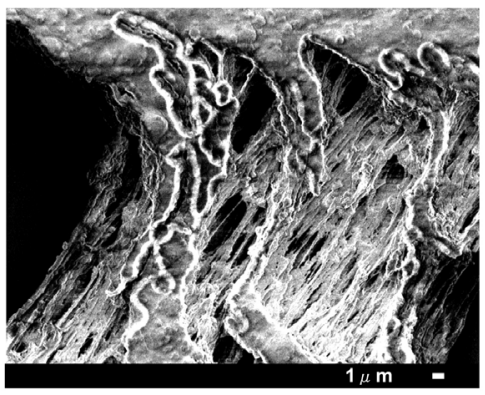

(b)

Figure 8. Field emission scanning electron micrographs of the fracture part of PPE/SBS xerogel with weight ratio of (a) SBS:PPE $=4: 1$ and (b) SBS:PPE $=4: 3$. 
dition of PPE which has poor solubility to naphthenic oil.

There have been many papers reporting morphological changes of SBS by forming oil gels. While the styrene blocks in SBS form spheres connected by the butadiene chains in dilute solutions, SBS forms lamellar structures in concentrated solutions or gels [1] [3] [5]-[8]. The drastic increases of E' which were observed for the SBS gels can be explained by the morphological changes. The SBS concentrations at which drastic increases of E' observed for the SBS gels with PPE were lower than those for the SBS gels without PPE. These results suggest that PPE induced not only the gelation, but also morphological changes of SBS.

E' of the SBS gels with PPE in naphthenic oil decreased at $0-4.8 \mathrm{wt} \%$, then drastically increased with an increase of PPE concentration around $9 \mathrm{wt} \%$. Considering that the morphological deformation of PS without oils by adding PPE has been reported in some papers [16] [17], it is also expected that the morphology of the styrene domains in the SBS gels is deformed by the addition of PPE. The decrease of E' can be explained if the deformed structure prevented the formation of a network structure of SBS.

The E' of the SBS gels with PPE decreased more slowly than that of the SBS gels without PPE with an increase of the temperature. This behavior can be explained by the coexistence of the styrene blocks including different amounts of PPE and having different Tgs [21]. It should be noted that similar temperature dependence of E' has been reported for the polymer blends of PS and PPE [16] [20] [21] [23].

The differences of the micrographs of SBS xerogel without PPE and SBS xerogels with PPE also suggest the structure transition of styrene domains by PPE addition. However it needs more detailed investigation to clarify the structure of SBS gels with PPE. For the investigation, new methods or techniques to analyze the amorphous with a large quantity of solvent are required. SBS and PPE are amorphous polymers, and the SBS gels with PPE or without PPE also have amorphous structure as shown in Figure 7 and Figure 8. Furthermore the SBS gels are rich in naphthenic oil. We tried to measure the structures and the Tgs of the SBS gels by using X-ray diffraction and differential scanning calorimetry, but no meaningful signals were observed. More detailed investigation of the structure of SBS in the gels will be carried out in our future work.

\section{Conclusion}

The melting temperature of SBS oil gels in naphthenic oil was successfully elevated by adding PPE, which has a high Tg, high affinity to the styrene blocks, and low affinity to the butadiene blocks. PPE was included into the styrene blocks in the SBS gels and elevated the Tg of the styrene blocks. The viscoelastic behaviors of the gels and SEM images suppose the structure transition of SBS gel with PPE.

\section{References}

[1] Laurer, J.H., Bukovnik, R. and Spontak, R.J. (1996) Morphological Characteristics of SEBS Thermoplastic Elastomer Gels. Macromolecules, 29, 5760-5762. http://pubs.acs.org/doi/abs/10.1021/ma9607271 http://dx.doi.org/10.1021/ma9607271

[2] Laurer, J.H., Mulling, J.F., Khan, S.A., Spontak, R.J., Lin, J.S. and Bukovnik, R. (1998) Thermoplastic Elastomer Gels. II. Effects of Composition and Temperature on Morphology and Gel Rheology. Journal of Polymer Science Part B: Polymer Physics, 36, 2513-2523. http://doi.wiley.com/10.1002/(SICI)1099-0488(199810)36:14<2513::AID-POLB5>3.3.CO;2-6 http://dx.doi.org/10.1002/(SICI)1099-0488(199810)36:14<2513::AID-POLB5>3.0.CO;2-T

[3] Laurer, J.H., Mulling, J.F., Khan, S.A., Spontak, R.J. and Bukovnik, R. (1998) Thermoplastic Elastomer Gels. I. Effects of Composition and Processing on Morphology and Gel Behavior. Journal of Polymer Science Part B: Polymer Physics, 36, 2379-2391. http://doi.wiley.com/10.1002/(SICI)1099-0488(19980930)36:13<2379::AID-POLB13>3.0.CO;2-0 http://dx.doi.org/10.1002/(SICI)1099-0488(19980930)36:13<2379::AID-POLB13>3.0.CO;2-0

[4] Dürrschmidt, T. and Hoffmann, H. (2001) Organogels from ABA Triblock Copolymers. Colloid \& Polymer Science, 279, 1005-1012. http://link.springer.com/10.1007/s003960100532 http://dx.doi.org/10.1007/s003960100532

[5] Walker, T.A., Semler, J.J., Leonard, D.N., van Maanen, G.J., Bukovnik, R.R., Spontak, R.J. (2002) ABA Triblock Copolymer Gels Modified with an A-Compatible Semicrystalline Homopolymer. Langmuir, 18, 8266-8270. http://pubs.acs.org/doi/abs/10.1021/la026117d http://dx.doi.org/10.1021/la026117d

[6] Sugimoto, M., Sakai, K., Aoki, Y., Taniguchi, T., Koyama, K. and Ueda, T. (2009) Rheology and Morphology Change 
with Temperature of SEBS/Hydrocarbon Oil Blends. Journal of Polymer Science Part B: Polymer Physics, 47, 955965. http://doi.wiley.com/10.1002/polb.21699

http://dx.doi.org/10.1002/polb.21699

[7] Chantawansri, T.L., Duncan, A.J., Ilavsky, J., Stokes, K.K., Berg, M.C., Mrozek, R.A., Lenhart, J.L., Beyer, F.L. and Andzelm, J.W. (2011) Phase Behavior of SEBS Triblock Copolymer Gels. Journal of Polymer Science Part B: Polymer Physics, 49, 1479-1491. http://doi.wiley.com/10.1002/polb.22335

http://dx.doi.org/10.1002/polb.22335

[8] Paglicawan, M.A., Balasubramanian, M. and Kim, J.K. (2007) Study on Nanocomposite Thermoplastic Elastomer Gels. Macromolecular Symposia, 249-250, 601-609. http://doi.wiley.com/10.1002/masy.200750443 http://dx.doi.org/10.1002/masy.200750443

[9] Kotaka, T. (1973) Rheological Properties of Solutions of Butadiene-Styrene Copolymers of Varying Microstructure. Journal of Rheology, 17, 587. http://scitation.aip.org/content/sor/journal/tsor/17/4/10.1122/1.549310 http://dx.doi.org/10.1122/1.549310

[10] Tuzar, Z., Petrus, V. and Kratochvíl, P. (1974) Sedimentation and Light Scattering Study of Block Copolymer Association. Die Makromolekulare Chemie, 175, 3181-3192. http://onlinelibrary.wiley.com/doi/10.1002/macp.1974.021751112/abstract http://dx.doi.org/10.1002/macp.1974.021751112

[11] Navarro, F.J., Martínez-Boza, F.J., Partal, P., Gallegos, C., Muñoz, M.E., Areizaga, J. and Santamaría, A. (2001) Effect of Processing Variables on the Linear Viscoelastic Properties of SBS-Oil Blends. Polymer Engineering \& Science, 41, 2216-2225. http://doi.wiley.com/10.1002/pen.10917 http://dx.doi.org/10.1002/pen.10917

[12] Machida, S., Takahashi, N., Matsuda, Y. and Tasaka, S. (2009) Aggregation Behavior of the Styrene Units in Oil Gel of Styrene-Butadiene-Styrene Triblock Copolymer. Nihon Reoroji Gakkaishi, 37, 25-29.

http://joi.jlc.jst.go.jp/JST.JSTAGE/rheology/37.25?from=CrossRef http://dx.doi.org/10.1678/rheology.37.25

[13] Wardlaw, K.R. and Shuler, S. (1992) Polymer Modified Asphalt Binders. ASTM International, West Conshohocken. http://dx.doi.org/10.1520/STP1108-EB

[14] Kamiya, S., Tasaka, S., Zhang, X., Dong, D. and Inagaki, N. (2001) Compatibilizer Role of Styrene-Butadiene-Styrene Triblock Copolymer in Asphalt. Polymer Journal, 33, 209-213. http://dx.doi.org/10.1295/polymj.33.209 http://www.nature.com/doifinder/10.1295/polymj.33.209

[15] Mazard, C., Benyahia, L. and Tassin, J.F. (2003) Dynamic Mechanical Properties of Polystyrene-Based Block Copolymers Blended with Poly(2,6-dimethyl-1,4-phenylene oxide). Polymer International, 52, 514-521.

http://doi.wiley.com/10.1002/pi.1073 http://dx.doi.org/10.1002/pi.1073

[16] Dikshit, A.K. and Kaito, A. (2003) Crystallization and Orientation Behaviors in Isotactic Polystyrene and Poly(2,6-dimethylphenylene oxide) Blends. Polymer, 44, 6647-6656. http://dx.doi.org/10.1016/i.polymer.2003.08.017 http://linkinghub.elsevier.com/retrieve/pii/S0032386103007808

[17] Mutsuda, M. and Omae, H. (2004) Morphological Transition of the Regular Structure of Poly(styrene-block-butadiene-block-styrene) at the Interface with Poly(xylenyl ether). Macromolecules, 37, 3346-3352.

http://pubs.acs.org/doi/abs/10.1021/ma035158t

http://dx.doi.org/10.1021/ma035158t

[18] Puskas, J.E., Kwon, Y., Altstädt, V. and Kontopoulou, M. (2007) Blends of Poly(2,6-dimethyl-1,4-phenylene oxide) (PPO) with Polystyrene-Based Thermoplastic Rubbers: A Comparative Study. Polymer, 48, 590-597. http://linkinghub.elsevier.com/retrieve/pii/S0032386106013000 http://dx.doi.org/10.1016/j.polymer.2006.11.045

[19] Oyama, H.T., Sekikawa, M. and Shida, S. (2012) Effect of the Interface Structure on the Morphology and the Mechanical, Thermal, and Flammability Properties of Polypropylene/Poly(phenylene ether)/Magnesium Hydroxide Composites. Polymer Degradation and Stability, 97, 755-765. http://linkinghub.elsevier.com/retrieve/pii/S0141391012000559 http://dx.doi.org/10.1016/j.polymdegradstab.2012.02.005

[20] Robertson, C. and Wilkes, G. (2000) Physical Aging Behavior of Miscible Blends Containing Atactic Polystyrene and Poly(2,6-dimethyl-1,4-phenylene oxide). Polymer, 41, 9191-9204. http://linkinghub.elsevier.com/retrieve/pii/S003238610000183X http://dx.doi.org/10.1016/S0032-3861(00)00183-X

[21] Lovera, D., Ruckdäschel, H., Göldel, A., Behrendt, N., Frese, T., Sandler, J.K.W., Altstädt, V., Giesa, R. and Schmidt, H.W. (2007) Tailored Polymer Electrets Based on Poly(2,6-dimethyl-1,4-phenylene ether) and Its Blends with Polystyrene. European Polymer Journal, 43, 1195-1201. http://linkinghub.elsevier.com/retrieve/pii/S0014305706004757 http://dx.doi.org/10.1016/j.eurpolymj.2006.12.032 
[22] Araki, Y., Hori, Y., Suzuki, K., Shirai, H., Kato, K. and Saito, H. (2014) Flexible and Flame-Retardant S-SEB-S Triblock Copolymer/PPE Nano-Alloy. Journal of Applied Polymer Science, 131, Published Online.

http://doi.wiley.com/10.1002/app.40446

http://dx.doi.org/10.1002/app.40446

[23] Saron, C. and Felisberti, M.I. (2004) Dynamic Mechanical Spectroscopy Applied to Study the Thermal and Photodegradation of Poly(2,6-dimethyl-1,4-phenylene oxide)/High Impact Polystyrene Blends. Materials Science and Engineering: A, 370, 293-301. http://linkinghub.elsevier.com/retrieve/pii/S0921509303008360

http://dx.doi.org/10.1016/i.msea.2003.01.001

[24] Creton, C., Halary, J. and Monnerie, L. (1999) Plasticity of Polystyrene-Poly(2,6,dimethy 1,1,4,phenylene oxide) Blends. Polymer, 40, 199-206. http://linkinghub.elsevier.com/retrieve/pii/S0032386198002067 http://dx.doi.org/10.1016/S0032-3861(98)00206-7

[25] Brandrup, J., Brandrup, J., Immergut, E.H., Grulke, E.A., Abe, A. and Bloch, D.R. (2003) Polymer Handbook. 4th Edition, John Wile \& Sons Inc., New York.

[26] The Solubility Parameter of Naphthenic Oil Was Provided from the Supplier. 
Scientific Research Publishing (SCIRP) is one of the largest Open Access journal publishers. It is currently publishing more than 200 open access, online, peer-reviewed journals covering a wide range of academic disciplines. SCIRP serves the worldwide academic communities and contributes to the progress and application of science with its publication.

Other selected journals from SCIRP are listed as below. Submit your manuscript to us via either submit@scirp.org or Online Submission Portal.
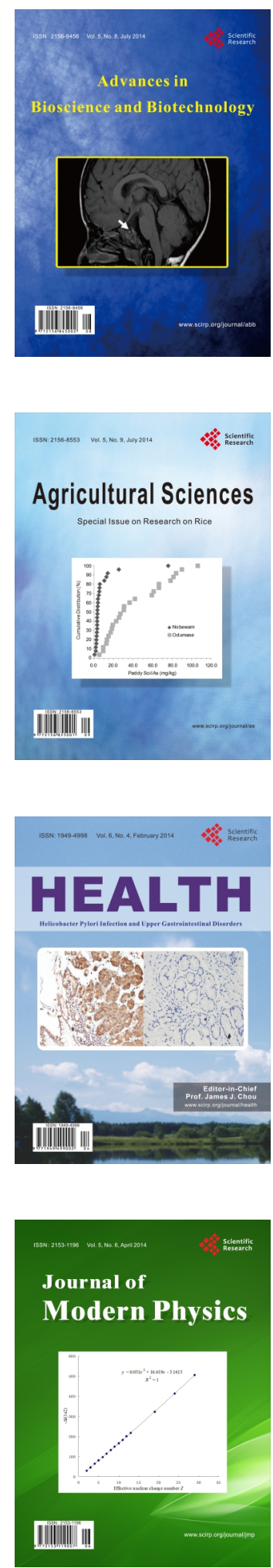
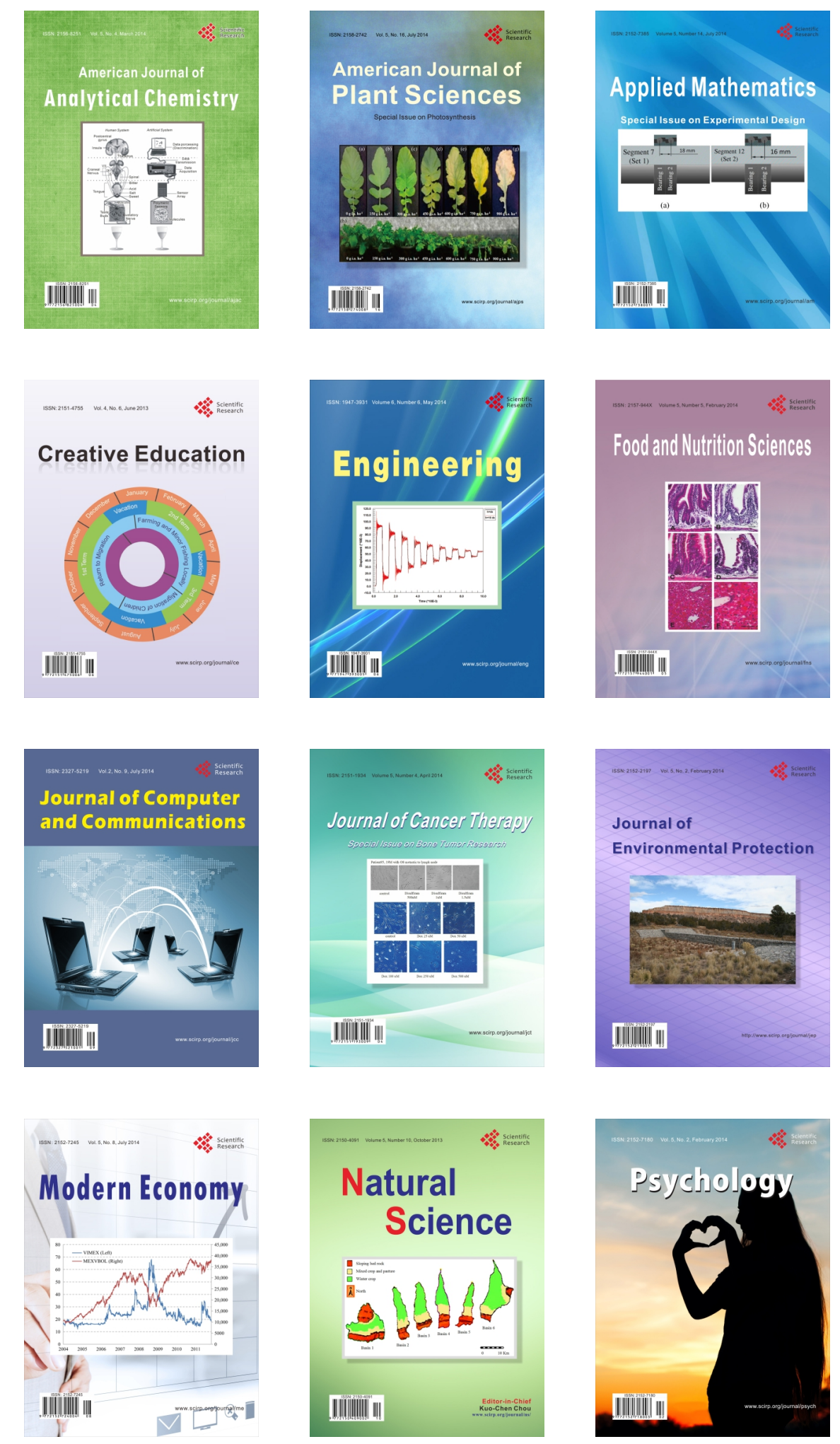